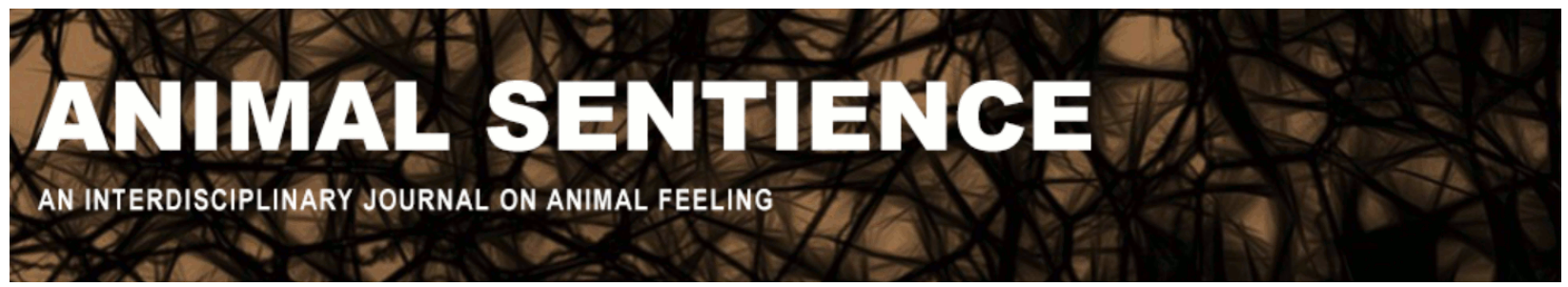

Tye, Michael (2016) Are insects sentient?. Animal Sentience 9(5)

DOI: $10.51291 / 2377-7478.1134$

Date of submission: 2016-08-04

Date of acceptance: 2016-08-06

(c) (i)

This article has appeared in the journal Animal

Sentience, a peer-reviewed journal on animal

cognition and feeling. It has been made open access,

free for all, by WellBeing International and deposited

in the WBI Studies Repository. For more information,

please contact

wbisr-info@wellbeingintl.org.

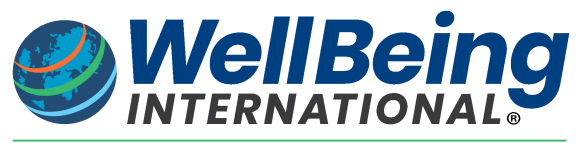

SOLUTIONS FOR PEOPLE, ANIMALS AND ENVIRONMENT 


\title{
Are insects sentient?
}

Commentary on Klein \& Barron on Insect Experience

\author{
Michael Tye \\ Department of Philosophy \\ University of Texas, Austin
}

\begin{abstract}
I comment on the methodology used by Klein \& Barron for dealing with the question of insect sentience and I briefly make a proposal of my own. Once it is granted that insects are sentient, a further question arises: which insects are subject to which states of sentience? Do insects feel pain, for example? If so, which ones? On the further question, I note, Klein \& Barron have nothing to say.
\end{abstract}

Michael Tye, professor of philosophy at University of Texas, Austin, does research on philosophy of mind, foundations of cognitive science, and metaphysics.

http://www.michaeltye.us

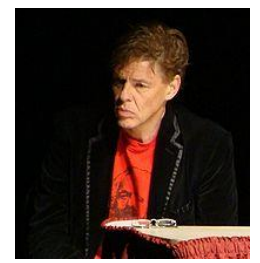

One way to try to get a grip on this question is by looking at commonalities between brain structures in insects and brain structures in animals we all agree are sentient, most notably ourselves. This is the strategy taken by Klein \& Barron (2016). It is sentience to which Klein \& Barron are referring when they use the term "subjective experience," and as they note, basic subjective experience is to be distinguished from other forms of consciousness, for example, higher-order consciousness (awareness that one is subject to such and such a mental state) and self-reflexive consciousness.

The immediate difficulty for Klein \& Barron's strategy is the lack of any general agreement as to what it is that makes a state phenomenally sentient. There are theories, to be sure. The preferred candidate of Klein \& Barron is that offered by Merker (2007). Unfortunately, this functional theory is contentious and those who doubt it will not find what Klein \& Barron say very persuasive. These opponents may well grant that there is a level of functioning of the sort specified by Merker that is supported by subcortical structures and goes along with sentience in creatures like us. But why take that to deliver sentience in every creature? After all, according to many philosophers and some scientists, sentience is one thing, functioning is another. So, you can have the latter without the former. It could be, then, that in some creatures, sentience is present once the relevant Merker conditions are met, whereas in others with neural differences of one sort or another, there is just the functioning and no glimmer of sentience itself.

It is the absence of an agreed upon theory of sentience that has led some researchers to take a view like that expressed by Marian Stamp Dawkins (2012) in the passage below: 
"Are animals conscious like us because they have many brain structures in common with us, or are they not like us because they lack some crucial pathway that prevents them from going that extra mile into conscious experience? Are they like us but only when we are using an evolutionary old unconscious route, or does a spark of what we would recognize as conscious experience flare in even the oldest of brains? On the basis of what we now know about human consciousness, both of these completely opposite views can be, and indeed have been, put forward as serious hypotheses." (p. 91)

An alternative strategy is to investigate animal meta-cognition. If animals behave in ways that indicate that they have a cognitive grasp of how things appear to them, and not just of how they are, then the obvious conclusion is that things really do appear to them in various ways. And if things appear to them, then the animals must be conscious of those things - they must experience them. This is a strategy proposed by Shea and Heyes (2010) and also by Allen and Bekoff (1997). What would count as evidence that an animal has a cognitive grasp on how things appear to it? A complex form of behavior providing such evidence would be using appearances to deceive other animals. A simpler form of behavior would be recognizing how something visually appears color-wise (where that appearance is different from the customary and real color of the thing) and matching the appearance to the real color of something else in order to get a reward.

In my view, this is a worthwhile and fruitful way to proceed. However, it is important to be clear on what it shows. If a positive result is obtained, then that is evidence that the animal is indeed sentient. But if a negative result ensues, what follows is only that higher-order consciousness has not been found. In such a case, the animal is not cognitively aware that it is undergoing such and such an experience. But that is perfectly compatible with the existence of sentience. Surely a one-year-old child can feel pain even though it is incapable of cognizing its state as painful.

A third strategy is to look at commonalities in behavior between the given animals and ourselves. Take the feeling of pain, for example. For us, there is a complex pattern of behavior that goes along with pain and is produced by it. If we can find a similar pattern in other creatures, that is a defeasible reason for believing that they experience pain too. Like effect, so like cause. There are defeaters to this reasoning, of course. Suppose, for example, during autopsy it is discovered that there is no brain in your head at all! That would lead to the conclusion that even though you behaved during your lifetime as if you had a host of experiences and feelings just like the rest of us, in reality you were some kind of android robot whose movements were controlled by others from outside so that it appeared as if you were conscious and indeed felt pain when in reality this was not so.

The case of insects is not like this. As Klein \& Barron observe, there are significant and interesting commonalities between insect brain structures and those of mammals. So, there is no immediate defeater from brain function. 
But do insects really behave as mammals do? It depends on the insect and it depends on the stimulus. One recent experiment (Bateson et al. 2011) supports the hypothesis that honeybees can feel anxious, for they behave as anxious people do in response to ambiguous stimuli. ${ }^{1}$ However, insects generally react very differently from us in response to noxious stimuli. They do not exhibit protective behavior towards injured parts; nor do they decline to mate or feed even in the presence of severe abdominal injuries. For example, tse-tse flies ignore extreme bodily injury and feed even if half-dissected. Further, locusts have been observed to continue to feed while being eaten by mantises. In general, insects do not react to treatment that would undoubtedly cause severe pain in mammals (see Eisemann et al. 1984). So, there is reason to doubt that generally insects feel pain.

It would have been good if Klein \& Barron had said some more about the various species of sentience they take to be present in insects and whether there are large differences here across the insect realm. Still, I find myself in sympathy with much of their discussion. ${ }^{2}$

\section{References}

Allen, C., \& Bekoff, M. (1997). Species of Mind: The Philosophy and Biology of Cognitive Ethology. Cambridge, MA: MIT Press.

Bateson, M., Desire, S., Gartside, S., \& Wright, G. (2011). Agitated honeybees exhibit pessimistic cognitive ciases. Current Biology, 21(12), 1070-1073.

Eisemann, C. H., Jorgensen, W. K., Merritt, D. J., Rice, M. J., Cribb, B. W., Webb, P. D., \& Zalucki, M. P. (1984). Do insects feel pain? A biological view. Experientia, 40, 164-167.

Klein, C., \& Barron, A. B. (2016). Insects have the capacity for subjective experience. Animal Sentience 2016.100.

Merker, B. (2007). Consciousness without a cerebral cortex: a challenge for neuroscience and medicine. Behavioral and Brain Sciences, 30, 63-81.

Shea, N., \& Heyes, C. (2010). Metamemory as evidence of animal consciousness: the type that does the trick. Biology and Philosophy, 25, 95-110.

Tye, M. (2016). Tense Bees and Shell-Shocked Crabs: Are Animals Conscious? Oxford University Press.

\footnotetext{
${ }^{1}$ Bateson and her co-authors resist this conclusion, saying only that the experiment provides evidence that honeybees can be in a state that is functionally like the feeling of anxiety. I see no reason for their caution. For more here, see Tye (2016).

${ }^{2}$ For a general discussion of insect consciousness, see Chapter 9 of Tye (2016).
} 